\title{
TELEVISÃO E CRENÇAS SOBRE A REALIDADE SOCIAL
}

\author{
Maria Paula Moreira ${ }^{1}$ \\ Maria Benedicta Monteiro ${ }^{2}$
}

Resumo: Este estudo teve como objectivo principal verificar a existência e a natureza da relação prevista entre a exposição à televisão e a percepção de determinados aspectos da realidade social, tais como medo de vitimação, desconfiança em relação aos outros e o locus de controlo, tal como foi teorizado por Gerbner e colaboradores na teoria de Cultivação de Crenças, enquanto efeito indirecto da exposição elevada à televisão. Foram inquiridos 226 jovens residentes na cidade de Lisboa, entre os 15 e 18 anos, tendo sido efectuadas ANOVAS sobre os valores obtidos nos três factores de percepção da realidade social encontrados, de modo a averiguar a existência de diferenças nas crenças dos jovens espectadores portugueses quanto ao modo como vêem o mundo à sua volta, no que respeita a sentimentos de medo, insegurança e desconfiança em relação aos outros, em função da exposição à televisão (tempo e conteúdos violentos) e das características sócio-demográficas dos participantes. Os resultados indicaram que, nesta amostra portuguesa, existe uma relação entre a exposição à televisão e algumas crenças sobre a realidade social, se bem que não tão linearmente como propuseram Gerbner e colaboradores ao lançarem as bases da Teoria de Cultivação de Crenças. No que respeita ao factor Medo Pessoal-Controlo Externo, a alta exposição à televisão tem efeitos contrários consoante o género dos telespectadores: Com o aumento do consumo televisivo para além de 3 horas diárias, só as raparigas acentuam a crença na possibilidade de serem vítimas, apelando mais à segurança através da intervenção das autoridades, enquanto que os rapazes muito assíduos não se percepcionam como prováveis vítimas de violência, aumentando mesmo a percepção de que podem eles próprios controlar essas situações. Não só o tempo de exposição total à televisão, mas também o tipo de programação preferido e visionado, estão igualmente associados às crenças que os jovens partilham: Os que assistem a mais programas violentos manifestam maior medo social, associado à percepção da capacidade individual para assegurar a autodefesa. Uma análise de regressão múltipla mostrou ainda que os três factores de crenças dos adolescentes sobre a realidade social que os rodeia tiveram como principal preditor o tempo de exposição à televisão.

\footnotetext{
${ }^{1}$ Instituto Superior de Psicologia Aplicada, Lisboa. E-mail: paula.bizarro@netcabo.pt

2 ISCTE, Instituto Universitário de Lisboa

PSICOLOGIA, Vol. XXIII (1), 2009, Edições Colibri, Lisboa, pp. 27-54
} 
Palavras-chave: violência, televisão, crenças, comunicação social, teoria da cultivação de crenças.

TV and beliefs about social reality (Abstract): This study aimed to understand the relationship between television viewing (time and violent content) and the construction of social beliefs regarding social reality, such as fear of victimization, interpersonal mistrust and locus of control, as suggested by Gerbner and his associates in the Cultivation Theory. Questionnaires were administrated to 226 students ranged in age from 15 to 18 . ANOVAS were conducted to explore the impact of television exposure, television violent content viewing, gender and family social status on the students' social beliefs. Results showed that the relationship between television exposure and some social beliefs exists, although not as linearly as defended by Gerbner and associates when launching the foundations of the Cultivation Theory. Among other results, on the personal fear-external control factor it was found that high television exposure had opposite effects on viewers according to their gender: While female heavy TV viewers were more fearful of being victims and more externally controlled, male heavy viewers generally tended to be less personally fearful and more internally controlled. To assess how well TV exposure (time and violent content), gender and family SES predicted social beliefs, a multiple regression analysis was conducted, and data indicated that TV viewing was a significant predictor of the three areas of social beliefs.

Key-Words: violence, television, mass media, cultivation theory.

\section{Introdução}

Muito se tem escrito acerca dos efeitos dos meios de comunicação social e em particular da televisão, desde que esta fez a sua inauguração pública. Existem razões para tal já que, se por um lado a televisão ocupa uma parte importante do nosso tempo mais do que qualquer outra forma de entretenimento (INE, 2001, 2002), por outro é evidente o papel central deste meio de comunicação na sociedade, como fonte de informação primordial para uma maioria acentuada da população (ISCTE/ ERC, 2007; Pew Research Center for People \& The Press, 2008). Com efeito, para a maior parte das pessoas com menos de 40 anos a exposição à televisão ocorreu na infância antes mesmo de saber ler ou falar. Este meio de comunicação de massa, ao contrário dos livros e dos jornais, é de fácil acesso e não requer literacia (no sentido mais estrito do termo, i.e., no que respeita ao suporte escrito da informação), nem mesmo de competências electrónicas necessárias aos jogos de computador e à utilização da Internet. Nos EUA estima-se 
que a televisão esteja ligada em média sete horas por dia e que cada membro de uma família americana consuma, em média, cerca de três horas diárias de televisão (Signorielli, 2005). A recente publicação de Shrum (2007) refere uma média aproximada de duas horas e quarenta minutos de consumo televisivo pelos adultos, enquanto que outros relatórios americanos continuam a apresentar uma média de visionamento diário na ordem das 3 horas para crianças e adolescentes (cf. American Academy of Pediatrics, 2001). Quando uma criança de hoje atingir a idade de 70 anos, passou 7 a 10 anos da sua vida "agarrada à televisão" (Strasburger, 1989, 2008). Um estudo da Kayser Family Foundation realizado com crianças (0-6 anos de idade) mostrou que, num dia típico, $65 \%$ viviam em lares onde a TV estava a transmitir mais de metade do tempo em que elas se encontravam em casa, sendo as próprias a ligar o aparelho de televisão $(77 \%)$, utilizavam o controlo remoto para mudar de canal (63\%), passando cerca de 2 horas diárias expostas a este meio de comunicação, o que corresponderia, segundo os autores, ao mesmo tempo que ocupavam a brincar no exterior (Rideout, Vandewater \& Wartella, 2003). Em Portugal a situação não é muito diferente: nos primeiros 9 meses de 2007, cada português assistiu em média em sua casa, a cerca 3 horas e meia de televisão por dia (Marktest Audimetria/MediaMonitor, 2007).

Como em muitos outros países, ver televisão é a actividade mais frequente das crianças portuguesas (ISCTE/ ERC, 2007). A televisão tem sido uma "ama" para muitas crianças e uma companhia para muitos adolescentes, substituindo por vezes a falta de disponibilidade dos pais para supervisionar e estar com os filhos, e podendo assumir funções reservadas, até ao presente, a instituições tais como a família e a escola, nomeadamente no que se refere aos benefícios educativos e informativos (ISCTE/ ERC, 2007).

Ao longo dos últimos anos, investigações interdisciplinares (Mastro, Behm-Morawitz \& Ortiz, 2007; Murray, 2007; Pecora, 2007) tentaram responder a questões relativas à forma como os meios de comunicação social podem influenciar o desenvolvimento de hábitos, comportamentos, ou mesmo a compreensão da realidade pelos espectadores. Uma das temáticas mais abordadas refere-se ao impacto da violência veiculada pela televisão e, mais recentemente, pelos jogos de vídeo ou de computador e pela Internet. Em particular, a violência na televisão tem sido uma matéria que, desde os anos 60 , continua a levantar questões relativamente à natureza e grau das suas consequências na sociedade e em particular nos seus membros mais jovens. A especial preocupação com a influência da televisão nas crianças e nos jovens está em grande parte relacionada com a suposta incapacidade e relativa falta de autonomia destes para lidarem com a exposição à violência e gerirem a explosão de informações, apresentada de forma apelativa e de fácil absorção, fornecida por este meio de comunicação. 
O tema da influência dos Meios de Comunicação Social gerou uma produção científica considerável nos últimos 40 anos, tendo-se desenvolvido explicações teóricas tais como a Teoria Catártica (Feshbach \& Singer,1971), que refere que as cenas de violência televisiva poderiam desempenhar um papel catártico (i.e., de purificação), por permitirem a descarga de uma agressividade latente, tornando as pessoas que a elas assistem menos propensas à agressão; a Teoria da Aprendizagem Social (Bandura, 1973, 1977; Bandura \& Walters, 1963) enfatizando o papel da aprendizagem por observação na aquisição e regulação dos comportamentos e a intervenção dos aspectos cognitivos na manutenção desses mesmos comportamentos aprendidos (i.e., se um agressor de um filme é punido pelos seus actos, há uma inibição consequente de comportamento agressivo por parte de quem assiste, mesmo que o comportamento tenha sido aprendido; por outro lado, quando o agressor observado não é punido ou é mesmo recompensado, as inibições da agressão diminuem e o observador tende a agredir, como aprendeu com o modelo); a Teoria da Agressão Reactiva (Berkowitz, 1962), mostrando que o recurso à agressão por quem já está emocionalmente activado por um estado de raiva pode aumentar ao assistir a filmes de conteúdos violentos; a Teoria da Dessensibilização (Linz, Donnerstein e Penrod, 1988), cujos estudos mostram que os espectadores de elevada violência na televisão podem tornar-se mais insensíveis à violência do mundo em que vivem; e a Teoria da Cultivação de Crenças (Cultivation Theory), que entende os media como inculcadores (i.e., "cultivadores") de crenças sobre a realidade social (Gerbner, 1972; Gerbner, Gross, Morgan \& Signorielli, 1986) e cujos estudos se centram nas alterações que os espectadores assíduos podem apresentar na sua percepção da realidade social em que se movem, assimilando essa realidade ao mundo violento do ecrã; a este tipo de percepção Wober (1978) chamou percepção paranóide do mundo e Signorielli (1990) o síndroma do mundo mau.

Iniciámos este trabalho tendo precisamente como referência o corpo teórico da teoria da cultivação de crenças, que se desenvolve com base na hipótese segundo a qual os media, em especial a televisão, são agentes de produção e reprodução de crenças e de representações da realidade social, contribuindo para o desenvolvimento de percepções distorcidas sobre a vida real (Gerbner, Gross, Morgan, Signorielli \& Shanahan, 2002). Esta teoria dos efeitos da exposição à TV sobre os espectadores foi desenvolvida por Gerbner e colaboradores que se interrogaram, não acerca dos efeitos directos comportamentais muito estudados na altura ${ }^{3}$, mas sobre os efeitos indi-

\footnotetext{
${ }^{3}$ Alguns estudos mostrando que a elevada exposição à violência pode levar ao recurso da agressão para resolução de conflitos: Bandura, (1973), Bandura \& Walters (1963) no seguimento da teoria da aprendizagem social; Berkowitz \& Rawlings (1963), Tannen-
} 
rectos, menos visíveis, mas com consequências importantes na formação e manutenção de sistemas de crenças sobre o mundo.

George Gerbner, sociólogo americano, conduziu durante mais de 40 anos uma série de trabalhos de forma a compreender o modo como a televisão nos afecta a todos. Os resultados dos seus estudos permitiram uma nova abordagem do fenómeno televisivo, nomeadamente no que se refere ao papel complexo, mas significativo, que a televisão e as histórias que esta conta desempenham nas nossas vidas. Para Gerbner (1990), o ser humano é a única criatura que vive num mundo construído pelas histórias que conta. Com efeito, a maior parte das coisas que nós sabemos ou pensamos, não foram experienciadas (isto é, vividas, por nós pessoalmente), mas ouvidas através de histórias que nos são contadas. E são precisamente essas histórias, a que nós chamamos arte, religião, educação, organização política e outras, que concorrem para a construção de uma rede de símbolos, chamada cultura. Para este autor, a cultura vai cultivar as nossas concepções sobre a existência, i.e., os valores, as relações humanas, a ideia de justiça, donde derivam as noções do que é importante, do que é bom ou mau (Gerbner, 1990). Com a difusão do uso da televisão, a maior parte das histórias já não é contada e difundida pelos agentes socializadores tradicionais, tais como os pais, a escola, a família, a igreja, ou mesmo pelos países de origem, mas por um grupo reduzido de organizações multimédia que têm algo a vender e o fazem através deste meio de comunicação. Quando são sempre as mesmas histórias, imagens, padrões, a ser exibidas pela televisão, uma e outra vez, os espectadores tendem a confundir o mundo ficcional da televisão com o mundo real. A teoria da cultivação de crenças de Gerbner (1990) defende precisamente que um dos principais efeitos da televisão é inculcar (i.e., cultivar) nos espectadores um conjunto de crenças sobre o mundo: ao contar historias, a televisão diz-nos como tudo funciona, o que se espera que cada um pense e faça. E os valores que a televisão enfatiza e sublinha são continuamente alimentados e sustentados durante muitas horas por dia. E não é um fenómeno que ocorra só num determinado momento (como é o efeito de um filme, por exemplo), não existindo um antes e um depois, já que a televisão está quase sempre presente no nosso quotidiano.

Gerbner e colaboradores (Gerbner et al., 2002) chamaram a atenção para o facto de haver constrangimentos comerciais que fazem com que a cobertura de determinados temas seja comum a quase todos os programas televisivos. Estes, por sua vez, cultivam pontos de vista comuns e estereótipos. A violência é um desses temas, e é especialmente importante na pers-

baum \& Zillmann (1975) e Zillmann,(1971), com base na teoria da activação emocional; Monteiro (1984); Vala (1984). 
pectiva da cultivação de crenças, porque as pessoas estão mais propensas a "experienciar" cenas de violência na televisão (quer seja em programas noticiosos ou de entretenimento) do que na vida real. Consequentemente, esta teoria defende que as concepções que as pessoas têm acerca da violência são mais susceptíveis de reflectir as mensagens de violência que vêem quotidianamente na televisão do que a sua própria experiência: Assim, os telespectadores mais assíduos irão tendencialmente percepcionar o mundo como um lugar assustador e mau, acreditando que o crime e a violência são mais frequentes do que realmente são, e tomar precauções para se protegerem da criminalidade (Gerbner, Gross, Morgan \& Signorielli, 1994). Esta nova abordagem, veio alargar o espectro das investigações sobre a televisão e a violência para além das pesquisas relativas à influência da televisão sobre o comportamento agressivo dos espectadores, levando a investigação a questionar a existência de consequências mais abrangentes do que é viver com um medium no qual as imagens de violência estão profunda e fatalmente presentes no nosso quotidiano (Signorielli, 1990; 2005). Em síntese, a teoria da cultivação de crenças vem tentando demonstrar que a televisão e a violência por ela difundida, para além da aprendizagem ou incitação a respostas agressivas, contribui para a produção e reprodução de crenças e de representações sobre a vida social.

A constatação destas preocupações levou-nos a tomar consciência da necessidade de trabalhos de investigação que possam contribuir para um maior esclarecimento dessas mesmas consequências e em particular identificar a potencial relação entre o modo como os jovens se expõem à televisão e o seu pensamento sobre a realidade social. Assim, iniciámos esta investigação procurando, primeiramente, responder à pergunta: "A televisão em Portugal tem uma acção significativa na cultivação de crenças dos adolescentes?" Temos pois, como objectivo principal, verificar a existência da relação prevista entre a exposição à televisão (tempo e conteúdos violentos) e as percepções dos adolescentes sobre determinadas dimensões da realidade social, nomeadamente quanto à visão de um mundo de perigo e maldade à sua volta, ao sentimento de medo e insegurança, à sua postura como vítimas, à protecção que exigem às autoridades, tal como defendido e teorizado por Gerbner e colaboradores na teoria de cultivação de crenças (Gerbner et al., 1986).

Nos últimos anos foi-se desenvolvendo uma série de investigações com base nesta teoria da cultivação de crenças, cuja hipótese é a de que quanto maior for o tempo de exposição ao mundo televisivo, maior será a probabilidade de os indivíduos apresentarem concepções da realidade social enviesadas em relação aos indicadores dessa mesma realidade social e mais próximas das que são veiculadas pela televisão. Vários estudos desenvolvidos com base na teoria de cultivação de crenças, sustentam que a exposição 
repetida às mensagens da TV sobre a realidade social (que nos estudos de Gerbner eram acima das 4 horas de televisão/dia) favorece a sua internalização, conduzindo nomeadamente a percepções exageradas acerca da prevalência da violência na sociedade (Gerbner, Gross, Signorielli, Morgan \& Jackson-Beeck, 1979; Gerbner, Gross, Morgan \& Signorielli, 1980a; Gerbner et al., 1986, 2002), ao desenvolvimento de crenças de que o mundo real é violento, mau e perigoso (Gerbner \& Gross, 1976; Gerbner et al., 1980a; Gosselin, DeGuise, Pacquette \& Benoit, 1997; Monteiro 1984,1990; Rubin, Perse \& Taylor, 1988; Signorielli, 1990; Vala, 1984; Wober \& Gunter, 1985); a uma maior desconfiança nas relações interpessoais (Gerbner \& Gross, 1976; Gerbner, Gross, Jackson-Beeck, Jeffries-Fox \& Signorielli, 1978, Gerbner, et al., 1979; Monteiro 1984, 1999; Vala, 1984), a um medo maior de vitimação (Bryant, Carveth \& Brown, 1981; Gerbner et al., 1980a; Eschholz, 2002; Monteiro 1984, 1990; Morgan, 1983; Vala, 1984) e tendência em sobrestimar a importância das instituições de controlo e ordem social (Gerbner et al., 1979; Monteiro, 1999).

À medida que as investigações se iam desenvolvendo, foi sendo progressivamente integrado um número crescente de tópicos, problemas e preocupações, tais como o papel de programas de televisão específicos na cultivação de crenças (Hawkins \& Pingree, 1981; Potter, 1990) e o contributo da televisão na construção das concepções relativamente: ao papel do sexo (Gerbner \& Signorielli, 1979; Morgan, 1982; Zaharopolous, 2000), aos estereótipos da idade, sendo que os jovens espectadores mais assíduos tendem a percepcionar os mais idosos em termos negativos e desfavoráveis, acreditando que "Os homens envelhecem mais devagar e desfrutam a vida durante mais tempo do que as mulheres" (Gerbner, Gross, Signorielli \& Morgan, 1980b) e estimativas acerca da percentagem de idosos existentes no mundo (Hetsroni, A., \& Tukachinsky, H., 2006), orientações politicas (Gerbner, Gross, Morgan \& Signorielli, 1982, 1984); problemas raciais (Volgy e Schwarz, 1980), à família (Gerbner, Gross, Morgan \& Signorielli, 1980c), religião (Hoover, 1990), estimativas de risco de vitimação relativamente a atentados terroristas, relâmpagos e inundações (Gunter \& Wober, 1983), estimativas sobre o número de mulheres a trabalhar fora de casa (Carveth \& Alexander, 1985), taxas de divórcio (Carveth \& Alexanders, 1985), maus hábitos de alimentação (Signorielli, N., 1992), eficácia do sistema de justiça para crime juvenis (Goidel, R., Freeman, C., \& Procopio, S., 2006), sendo no entanto na área da violência e do medo que as análises da cultivação de crenças mais se têm centrado.

A meta-análise de Shanahan \& Morgan (1999), que incidiu sobre 5633 resultados referentes a 97 estudos conduzidos ao longo de duas décadas e realizados com base na teoria da cultivação, revelou existir uma relação significativa entre a exposição à televisão e a cultivação de crenças 
sobre o mundo, porém, de fraca magnitude (0.10). Mas para os autores, esta "meta correlação" é relevante e pode fazer a diferença, se pensarmos que os efeitos da exposição à televisão são cumulativos.

O presente estudo visa contribuir para um melhor conhecimento do impacto da televisão em Portugal sobre os jovens e aborda as seguintes questões: 1) Existem diferenças nas percepções dos jovens portugueses acerca de determinadas dimensões da realidade social (nomeadamente quanto à visão de um mundo de perigo e maldade à sua volta, ao sentimento de medo e insegurança, à sua postura como vítimas e à protecção que exigem às autoridades) em função da exposição à televisão (tempo e conteúdos violentos) e das características sociodemográficas dos participantes, em separado ou em interacção, tal como previsto na teoria da Cultivação de Crenças, por Gerbner e seus colaboradores (Gerbner et al., 1986; Morgan \& Signorielli, 1990)? 2) Qual a contribuição do tempo de exposição à televisão, da exposição a violência televisiva, do género e do nível socioprofissional dos pais, para explicar as diferenças nas crenças dos adolescentes e quais são os preditores mais significativos das crenças dos adolescentes?

\section{Método}

\section{Participantes}

Participaram neste estudo 226 estudantes do ensino secundário (53,5\% do sexo feminino) frequentando quatro escolas públicas da cidade de Lisboa, com idades compreendidas entre os 15 e os 18 anos $(M=16,69$; $D P=1,03)$ e pertencendo maioritariamente a famílias de nível sócio profissional médio (N.S.P.). ${ }^{4}$

\section{Instrumento}

A fim de avaliarmos se ver muita ou pouca televisão contribui para a forma como os jovens percepcionam a realidade social, foi utilizado um questionário que, para além das questões sociodemográficas, pretendeu medir as seguintes variáveis: a percepção da realidade social relativa ao medo de vitimação; a desconfiança em relação aos outros; e o locus de controlo, interno ou externo, face à ameaça de vitimação; o tempo de exposição diária à televisão; e a exposição à programação violenta.

\footnotetext{
${ }^{4}$ O nível sócio-profissional dos pais baseou-se na Classificação Internacional por Tipos de Profissões (CITP), cujas categorias foram posteriormente simplificadas e reduzidas a 3 níveis - alto, médio e baixo.
} 


\section{Percepção da realidade social}

Esta variável foi avaliada através de 16 questões integradas nas três dimensões teóricas da hipótese de Cultivação de Crenças relativamente à percepção da realidade social: o medo de vitimação (dicotomizado, de acordo com Tyler (1984), em medo pessoal e social (e.g., "Sinto-me seguro(a) ao andar sozinho(a) no meu bairro", "A probabilidade de uma pessoa sozinha ser vítima de roubo ao andar de comboio ou metro à noite é mínima"); a desconfiança em relação aos outros (e.g., "É difícil confiar nas pessoas; todo o cuidado é pouco ao lidar com elas") e o locus de controlo, interno ou externo, face à ameaça de vitimação (Wober \& Gunter, 1982) (e.g., "O controlo da minha vida pertence sobretudo a mim; sou eu o responsável pelo meu destino.", "Compete sobretudo às Autoridades tomar medidas eficazes de defesa em relação à segurança física e dos bens dos cidadãos, já que os indivíduos pouco podem fazer contra este tipo de violência"). Os jovens responderam aos 16 itens sobre uma escala de intervalo em cinco posições de acordo com a intensidade da crença sobre a realidade social, desde Discordo em Absoluto (1) até Concordo em Absoluto (5).

\section{Tempo de exposição à televisão}

Para a avaliação desta variável foi pedido aos participantes que especificassem quantas horas de televisão haviam visto no dia anterior (" Quantas horas passaste ontem a ver televisão?") e num dia de semana normal ("Quantas horas de televisão costumas ver num dia de escola?"), sendo esta última questão a mais utilizada em estudos de cultivação de crenças para medir a exposição à televisão (Morgan, 1983; Signorielli, 1990; Volgy \& Schwarz, 1980). Quisemos igualmente avaliar qual a melhor medida de tempo de exposição à televisão a adoptar: se os índices simples (quantas horas de televisão vistas no dia anterior, ou estimativa do número de horas de exposição num dia de escola), se o compósito, utilizado por Rubin, Perse \& Taylor (1988) referente à média dos dois índices acima referidos.

Tendo em conta o desvio padrão apresentado para cada índice, simples e compósito ${ }^{6}$ (por forma a obter a medida que melhor descrimina), a correlação entre os vários índices de medida de exposição à televisão ${ }^{7} \mathrm{e}$ tendo presente o principio da parcimónia, adoptámos como medida da exposição à televisão o tempo dispendido no dia anterior a ver televisão.

\footnotetext{
5 A recolha dos dados decorreu entre $3^{\mathrm{a}}$ e $6^{\mathrm{a}}$ feira.

6 Televisão ontem $\left(M_{\text {tv ontem }}=2,07, D P\right.$ tv ontem $\left.=1,28\right)$; Televisão que costuma ver num dia de escola $\left(M_{\mathrm{tv}}\right.$ dia $=2,75, D P_{\mathrm{tv}}$ dia $\left.=1,23\right) ;(\mathrm{TV}$ ontem+TV dia $) / 2 \quad\left(M_{\mathrm{tv}}=2,41\right.$, $\left.D P_{\mathrm{tv}}=1,19\right)$.

${ }^{7}$ A correlação entre o tempo de televisão visto na véspera e o tempo de televisão visto num dia de escola é de $0,80, p<0,001$.
} 
Posteriormente e a partir da distribuição da amostra, os jovens foram agregados em três grupos de acordo com a sua assiduidade televisiva: assiduidade alta - assistem a 3 horas ou mais de televisão por dia; assiduidade média - assistem a mais do que 1 hora e menos do que 3 horas diárias; assiduidade baixa - assistem a 1 hora ou menos de televisão por dia.

\section{Exposição a programação violenta}

Foi pedido aos participantes que indicassem por ordem decrescente os três programas a que mais assistiam na televisão, procedendo-se em seguida a um processo de classificação daqueles programas em duas categorias $^{8}$ - Programação violenta e não violenta, tendo por base a definição de violência: "Quando é manifesta e clara a intenção de prejudicar, lesar, ferir elou matar o outro ou o próprio, através de força física (com ou sem armas) ou mesmo psicológica, com consequências nefastas credivelmente graves" (Signorielli, 1990). Posteriormente, as respostas dos participantes foram agrupadas em três categorias de acordo com a assiduidade a programação televisiva violenta (i.e. em função do número de programas violentos escolhidos): alta exposição a violência televisiva (2 e 3 escolhas, $N=101$ ), média exposição a violência televisiva (1 escolha, $N=91)$ e baixa exposição a violência televisiva ( 0 escolhas, $N=32$ ).

\section{Procedimento}

O questionário foi apresentado como fazendo parte de um estudo de opinião sobre algumas questões relativas à vivência social dos jovens portugueses e suas preferências e hábitos de consumo televisivos, e a ele responderam os alunos que para tal se voluntariaram.

O questionário foi administrado colectivamente nas salas de aula das escolas seleccionadas, durante o horário escolar e com a presença de uma investigadora e um professor da turma. A sua aplicação teve uma duração aproximada de 20 minutos.

\footnotetext{
${ }^{8}$ A classificação foi feita por três juízes, de forma independente e as que foram retidas foram as que obtiveram um consenso de cem por cento.
} 


\section{Resultados}

\section{Tempo de exposição à televisão}

Os jovens da nossa amostra assistem, em média, a cerca de 2 horas de televisão por dia $(M=2,07, D P=1,28)$, sendo os rapazes espectadores mais assíduos $(M=2,26, D P=1,39)$ do que as raparigas $(M=1,90, D P=1,17)$ num dia útil, [ $t(224)=2,07, p<0,05]$. Este resultado é menor do que o encontrado no estudo de Kuntsche, Picket, Overpeck, Craig, Boyce e Gaspar de Matos (2006), o qual refere uma média de visionamento próximo das 3 horas diárias para os adolescentes de oito países, entre os quais portugueses $(M=2,89, D P=1,8)$ e americanos $(M=2,73, D P=2,0)$.

Constatámos igualmente que são os jovens oriundos de famílias de nível sócio-profissional mais baixo que passam mais tempo a ver televisão $(M=2,94, D P=1,45)$, comparativamente aos de nível médio $(M=1,88$, $D P=1,19)$ e alto $(M=1,72, D P=0,99),[F(2,224)=18,48, p<0,001]$.

\section{Exposição a programação televisiva violenta}

Verificou-se que a maioria dos espectadores $(45,1 \%)$ têm uma exposição alta a programação televisiva de conteúdo violento, não se registando diferenças significativas entre rapazes e raparigas $\left[\chi^{2}(2,224)=1,227\right.$, $p=0,541]$, nem entre os diferentes níveis sócio-profissionais $\left[\chi^{2}(4,224)\right.$ $=1,755, p=0,781]$.

\section{Dimensões da percepção da realidade social}

Para compreender e sistematizar a estrutura de pensamento dos jovens sobre a realidade social, realizou-se uma análise ${ }^{9}$ factorial em componentes principais (Quadro 1) que identificou 3 factores, que explicam, em conjunto, $40,2 \%$ da variância total.

O primeiro factor, Medo Pessoal - Controlo Externo associa os sentimentos de medo de ser pessoalmente vitimado, a uma crença na impotência individual e no poder das forças externas (a Autoridade) para proteger os indivíduos da violência. Esta dimensão está ligada a explicações externas no que respeita ao controlo da própria vida, isto é, o indivíduo com maior receio de ser vítima a nível pessoal é aquele que percepciona um acontecimento como não sendo determinado pelas suas acções, mas antes o resultado do acaso ou como um feito de outros mais poderosos, fugindo-lhe pois ao controlo. Este primeiro factor explica $17,8 \%$ da variância das respostas dos participantes e apresenta uma boa consistência interna $(\alpha=0,73)$.

\footnotetext{
${ }^{9}$ Procedeu-se a uma análise factorial em componentes principais, com rotação ortogonal dos eixos e retenção das variáveis com saturação superior a 0,50 num só factor.
} 
Quadro 1. Estrutura factorial das crenças sobre a violência e a realidade social

\begin{tabular}{|c|c|c|c|}
\hline & $\begin{array}{c}\text { Factor } \\
1\end{array}$ & $\begin{array}{c}\text { Factor } \\
2\end{array}$ & $\begin{array}{c}\text { Factor } \\
3\end{array}$ \\
\hline \% da variância $($ Total $=40,20$ \%) & 17,83 & 13,09 & 9,28 \\
\hline Alfa de Cronbach & 0,73 & 0,60 & $\mathbf{0 , 5 1}$ \\
\hline
\end{tabular}

\section{Medo Pessoal - Controlo Externo}

- Sinto-me seguro(a) ao andar sozinho(a) no meu bairro.

$\begin{array}{lll}\mathbf{- 0 , 7 6} & -0,07 & -0,09 \\ \mathbf{0 , 6 9} & 0,06 & -0,01 \\ \mathbf{0 , 6 4} & 0,02 & 0,23 \\ \mathbf{- 0 , 6 3} & -0,06 & 0,06 \\ \mathbf{- 0 , 6 3} & -0,04 & 0,06 \\ & & \\ \mathbf{0 , 5 6} & -0,01 & -0,11\end{array}$

- Sinto-me receoso(a) se tiver que andar sozinho(a) de metro ou de comboio à noite.

- É cada vez mais provável eu ser assaltado(a) à noite no meu bairro.

- Nunca deixei de sair à noite sozinho(a) por medo de ser assalta-

do(a) ou vítima de qualquer outro crime

- O controlo da minha vida pertence sobretudo a mim; sou eu o

responsável pelo meu destino.

- Compete sobretudo às Autoridades tomar medidas de defesa

eficazes em relação à segurança física e dos bens dos cidadãos, já

que os indivíduos pouco podem fazer contra este tipo de violência.

\section{Desconfiança em relação aos outros}

- Sei que posso contar com os outros sempre que tenho um problema grave.

$\begin{array}{lll}-0,02 & \mathbf{- 0 , 7 4} & 0,11 \\ 0,07 & \mathbf{0 , 7 1} & 0,16 \\ 0,05 & \mathbf{0 , 6 3} & 0,13 \\ 0,02 & \mathbf{- 0 , 6 1} & 0,29\end{array}$

\section{Medo Social - Controlo Interno}

- As hipóteses de uma criança ser vítima de rapto ou de agressão sexual ao brincar frequentemente sozinha num parque, é mínima.

$\begin{array}{lll}-0,08 & -0,19 & \mathbf{- 0 , 6 8} \\ -0,09 & 0,04 & -\mathbf{0 , 6 7} \\ -0,22 & -0,03 & \mathbf{0 , 6 1}\end{array}$
andar de comboio ou metro à noite, é mínima. 
O segundo factor, denominado Desconfiança em relação aos outros, agrega crenças acerca das relações interpessoais (falta de generosidade e disponibilidade dos outros para ajudar) e a atitude de desconfiança que os outros merecem. Este factor explica $13,1 \%$ da variabilidade das respostas dos participantes e apresenta uma consistência interna razoável $(\alpha=0,60)$.

O terceiro factor, Medo Social - Controlo Interno conjuga a percepção de medo a nível social (pressupondo a existência de violência e crime na sociedade em geral, sem que o medo seja personalizado) com a crença na virtualidade positiva da autodefesa. Esta dimensão está ligada a uma percepção de controlo interno, querendo isto dizer que num indivíduo onde é patente um sentimento de medo de violência num sentido mais social do que pessoal, se associa a crença de que o controle dos acontecimentos pode depender do seu próprio comportamento ou das suas características pessoais. Este terceiro factor explica $9,3 \%$ da variância total das respostas e uma consistência interna aceitável $(\alpha=0,51)$ pelo facto de ser composto por apenas três itens.

Verificou-se, pois, uma congregação de indicadores de desconfiança, falta de generosidade e disponibilidade dos outros, já encontrada em estudos anteriores (Vala, 1984; Monteiro, 1984, 1999; Gerbner et al., 1979; Rubin et al., 1988), e uma associação dos sentimentos de medo de vitimação pessoal a crenças de controlo externo, e conjugação dos sentimentos de medo social a crenças de controlo interno.

Tendo em conta que a média ${ }^{10}$ da escala teórica é igual a 3, verifica-se que no factor Medo Social - Controlo Interno, os sujeitos exprimem um nível acentuado de medo de vitimação social, embora associado à crença na capacidade individual de assegurar a autodefesa $(M=3,81, D P=0,67)$. No que diz respeito aos outros dois factores, os jovens, exprimem de forma moderada o Medo Pessoal-Controlo Externo $(M=3,03, D P=0,78)$, bem como a crença na falta de disponibilidade e generosidade das pessoas para ajudarem os outros aliado ao sentimento de Desconfiança que os outros merecem $-(M=3,09, D P=0,65)$.

\section{Consumo de televisão e crenças sobre a realidade social}

Para responder à primeira questão do nosso estudo, nomeadamente se existem diferenças nas crenças dos jovens espectadores portugueses quanto ao modo como vêem o mundo à sua volta no que respeita a sentimentos de medo, insegurança e desconfiança em relação aos outros, em função da exposição à televisão (tempo e conteúdos violentos) e das características

$10 \mathrm{O}$ valor que os participantes tiveram em cada factor foi obtido a partir da média simples dos itens que os integram. 
sociodemográficas dos participantes, em separado ou em interacção, realizámos ANOVAs ${ }^{11}$ aos três factores da percepção da realidade social encontrados.

1. Tempo de exposição à televisão e crenças sobre a realidade social - realizámos, num primeiro momento, três ANOVAs, uma sobre cada um dos três factores da percepção da realidade social encontrados, correspondente ao seguinte plano: Tempo de exposição (assiduidade alta, assiduidade média, assiduidade baixa) $x$ Género (rapazes, raparigas) $x$ N.S.P (alta, média, baixa), tendo sido verificado como mais relevantes os seguintes resultados:

No que respeita ao Medo Pessoal-Controlo Externo, foram observados efeitos principais do género $(F(1,225)=13,29, \quad p<0,001$, $\left.M S E=0,463, \eta^{2}=0,060\right)$ e do tempo de exposição à televisão $(F(2,225)$ $\left.=7,99, p<0,001, M S E=0,463, \eta^{2}=0,072\right)$. Registou-se igualmente um efeito de interacção entre o género dos espectadores e o tempo de exposição ao pequeno ecrã $\left(F(2,225)=17,63, p<0,001, M S E=0,463, \eta^{2}=0,146\right)$.

No que diz respeito ao sexo, ambos os grupos exprimiram níveis moderados de Medo Pessoal-Controlo Externo, mas foram precisamente as raparigas que se diferenciaram positivamente, acentuando o medo de serem vítimas, apelando mais à segurança através da intervenção das Autoridades do que os rapazes (Quadro 2).

Quadro 2. Género e crenças sobre a realidade social.

\begin{tabular}{lcccccc}
\hline $\begin{array}{l}\text { Percepção da reali- } \\
\text { dade social }\end{array}$ & \multicolumn{3}{c}{ Rapazes } & \multicolumn{3}{c}{ Raparigas } \\
\cline { 2 - 7 } & $\mathbf{N}$ & média & d.p. & N & média & d.p. \\
\hline $\begin{array}{l}\text { Medo Pessoal - Con- } \\
\text { trolo Externo }\end{array}$ & 105 & $2,81^{\mathrm{a}}$ & 0,79 & 120 & $3,22^{\mathrm{b}}$ & 0,72 \\
$\begin{array}{l}\text { Desconfiança } \\
\begin{array}{l}\text { Medo Social - Con- } \\
\text { trolo Interno }\end{array}\end{array}$ & 104 & $3,10^{\mathrm{a}}$ & 0,68 & 120 & $3,09^{\mathrm{a}}$ & 0,62 \\
& 104 & $3,86^{\mathrm{a}}$ & 0,69 & 121 & $3,76^{\mathrm{a}}$ & 0,64 \\
\end{tabular}

Nota: as médias, na mesma linha, com letras diferentes, são significativamente diferentes entre si a $p<0,05$; escala de $1=$ discordo em absoluto, a $5=$ concordo em absoluto.

11 Devido ao facto dos três factores não estarem correlacionados, optou-se por três ANOVAs independentes, uma para cada factor. 
O efeito principal observado da exposição à televisão vai no sentido de os jovens que assistiram a mais do que uma hora de televisão por dia apresentarem um maior nível de Medo Pessoal-Controlo Externo do que os jovens menos assíduos (Quadro 3).

Quadro 3. Tempo de exposição à TV e crenças sobre a realidade social.

\begin{tabular}{|c|c|c|c|c|c|c|c|c|c|}
\hline \multirow[t]{2}{*}{$\begin{array}{l}\text { Percepção da } \\
\text { realidade social }\end{array}$} & \multicolumn{3}{|c|}{$\begin{array}{c}\text { Assiduidade } \\
\text { baixa } \\
\text { ( } \leq 1 \text { hora) }\end{array}$} & \multicolumn{3}{|c|}{$\begin{array}{l}\text { Assiduidade } \\
\text { média } \\
\text { (1 - } 3 \text { horas })\end{array}$} & \multicolumn{3}{|c|}{$\begin{array}{c}\text { Assiduidade } \\
\text { alta } \\
\text { ( } \geq 3 \text { horas })\end{array}$} \\
\hline & $\mathbf{N}$ & média & d.p. & $\mathbf{N}$ & média & d.p. & $\mathbf{N}$ & média & d.p. \\
\hline $\begin{array}{l}\text { Medo Pessoal - } \\
\text { Controlo Externo }\end{array}$ & 81 & $2,81^{\mathrm{a}}$ & 0,77 & 73 & $3,17^{\mathrm{b}}$ & 0,66 & 71 & $3,13^{b}$ & 0,85 \\
\hline Desconfiança & 81 & $2.96^{\mathrm{a}}$ & 0,54 & 73 & $3,02^{\mathrm{a}}$ & 0,58 & 70 & $3,32^{b}$ & 0,76 \\
\hline $\begin{array}{l}\text { Medo Social - } \\
\text { Controlo Interno }\end{array}$ & 80 & $3,61^{\mathrm{a}}$ & 0,67 & 74 & $3,78^{\mathrm{a}}$ & 0,65 & 71 & $4,07^{b}$ & 0,60 \\
\hline
\end{tabular}

Nota: as médias, na mesma linha, com letras diferentes, são significativamente diferentes entre si.

No entanto, estes efeitos principais são qualificados pela interacção entre o género dos espectadores e o tempo de exposição ao pequeno ecrã, sendo que a alta exposição à televisão teve efeitos contrários nos rapazes e raparigas: com o aumento da exposição à televisão para mais de 3 horas por dia, só as raparigas acentuaram a crença na possibilidade de serem vítimas, apelando mais à segurança através da intervenção das autoridades, $\left(M_{\text {assid, }}\right.$,

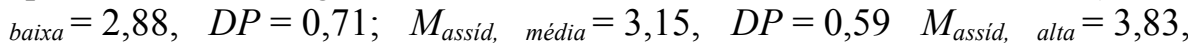
$D P=0,46)(F(2,119)=22,85, p<0,001)$ enquanto que os rapazes, no mesmo grupo, reduziram o nível de medo de vitimação pessoal, não se percepcionando como prováveis vítimas de violência ao mesmo tempo que a ideia da incontrolabilidade pessoal e a necessidade de forças sociais para os proteger em caso de violência, é menos acentuada $\left(M_{\text {assid, baixa }}=2,72\right.$, $\left.D P=0,85 ; M_{\text {assid, média }}=3,20, D P=0,75 ; M_{\text {assid, alta }}=2,58, D P=0,67\right)(F(2$, $104)=6,36, p=0,002)($ Figura 1).

Relativamente ao factor Desconfiança, foi observado um efeito principal do tempo de exposição à televisão $[F(2,224)=5,04, p=0,007$, $\left.M S E=0,372, \eta^{2}=0,047\right]$, que se traduz no facto de os telespectadores mais assíduos (que assistiam a 3 ou mais horas de televisão por dia) revelarem níveis de Desconfiança mais elevados $\left(M_{\text {assiduid. alta }}=3,32\right.$, D.P. $\left.=0,76\right)$ do 
que os espectadores de assiduidade média $(M=3,02, D P=0,58)$ e baixa $(M=2,96, D P=0,54)$ (Quadro 3).

Figura 1. Medo Pessoal-Controlo Externo em função do tempo de exposição à TV e do género dos participantes

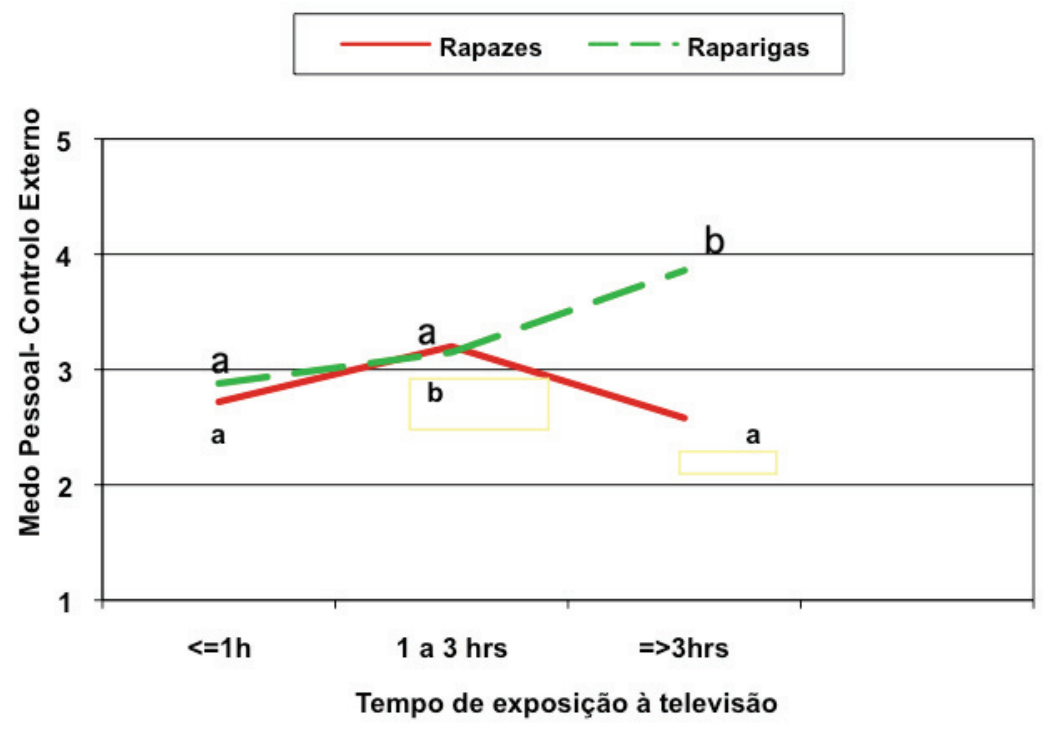

Nota: Médias, por género, com letras diferentes, são diferentes entre si $(p<0,05)$.

Observou-se igualmente um efeito principal do N.S.P. no factor Desconfiança, $\left(F(2,224)=2,25, p=0,040, M S E=0,372, \eta^{2}=0,021\right)$ em que os resultados apontam para que os participantes de famílias de nível sócio-profissional mais baixo desconfiem mais dos outros, comparativamente aos pertencentes ao nível socioprofissional médio e alto, (Quadro 4).

Ainda relativamente à Desconfiança, verificou-se igualmente um efeito de interacção entre o tempo de exposição à televisão e o estatuto sócio-profissional dos pais, $[F(4,224)=2,57, p=0,039, M S E=0,372$, $\left.\eta^{2}=0,048\right]$. Utilizámos o teste Tukey para identificar entre que grupos se encontravam as diferenças e verificámos que o efeito do tempo de exposição à televisão se exercia mais sobre os jovens cujos pais pertencem ao grupo médio do N.S.P. Assim, foram os telespectadores mais assíduos de famílias pertencentes a um nível sócio-profissional médio que exprimiram de forma mais acentuada falta de confiança nos outros, $\left(M_{\text {assid, alta }}=3,40\right.$, $D P=0,73)$ em comparação com os espectadores menos assíduos $\left(M_{\text {assid, }}\right.$ 


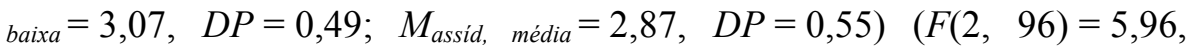
$p=0,004, M S E=0,343)$.

Quadro 4. Nível sócio-profissional da família (N.S.P.) e crenças sobre a realidade social.

\begin{tabular}{|c|c|c|c|c|c|c|c|c|c|}
\hline \multirow{2}{*}{$\begin{array}{l}\text { Percepção da } \\
\text { realidade social }\end{array}$} & \multicolumn{3}{|c|}{ N.S.P. alto } & \multicolumn{3}{|c|}{ N.S.P. médio } & \multicolumn{3}{|c|}{ N.S.P. baixo } \\
\hline & $\mathbf{N}$ & média & d.p & $\mathbf{N}$ & média & d.p & $\mathbf{N}$ & média & d.p. \\
\hline $\begin{array}{l}\text { Medo Pessoal - } \\
\text { Controlo Externo }\end{array}$ & 77 & $2,93^{\mathrm{a}}$ & 0,75 & 96 & $3,08^{\mathrm{a}}$ & 0,74 & 52 & $3,07^{\mathrm{a}}$ & 0,88 \\
\hline Desconfiança & 77 & $2,95^{\mathrm{a}}$ & 0,55 & 97 & $3,01^{\mathrm{a}}$ & 0,61 & 50 & $3,34^{\mathrm{b}}$ & 0,77 \\
\hline $\begin{array}{l}\text { Medo Social - } \\
\text { Controlo Interno }\end{array}$ & 76 & $3,68^{\mathrm{a}}$ & 0,61 & 97 & $3,79^{\mathrm{ab}}$ & 0,72 & 52 & $4,03^{b}$ & 0,62 \\
\hline
\end{tabular}

Nota: As médias, na mesma linha, com letras diferentes, são significativamente diferentes entre si.

No que respeita ao Medo Social-Controlo Interno dos jovens, observou-se um efeito principal do tempo de exposição à televisão $(F(2,225)=$ $5,29, \mathrm{p}=0,006, M S E=0,422,\left(\eta^{2}=0,049\right)$ : quanto maior era o consumo televisivo, mais se acentuou o medo social (i.e., temendo-se mais pela segurança das crianças que brincam sozinhas nos parques, elevando-se a crença de uma maior probabilidade de se ser vítima ao andar à noite em transportes públicos), embora associado à percepção na capacidade individual de enfrentar a violência (Quadro 3).

Verificou-se igualmente que eram os jovens oriundos de famílias de nível sócio-profissional mais baixo que exprimiam níveis mais acentuados de Medo Social-Controlo Interno, comparativamente aos jovens oriundos de famílias de nível sócio profissional mais elevado $[F(2,224)=3,86$, $\left.p<0,022), \eta^{2}=0,034\right]$ (Quadro 4). Se aliarmos este resultado aquele observado no factor desconfiança e se assumirmos que estes grupos de jovens com pais pertencentes a um nível socioprofissional inferior está ligado a um menor poder aquisitivo, poderemos pensar que a elevada exposição à televisão estará igualmente relacionada com uma falta de alternativa de locais onde ir; desta forma, esta parcela da audiência estará mais propensa à construção de um mundo semelhante àquele que lhe é exposto quotidianamente pelos canais de televisão, apresentando uma percepção paranóide do mundo (Wober, 1978), onde as relações interpessoais são de desconfiança, exprimindo com maior intensidade a crença num mundo onde o perigo de 
vitimação social é real, associada à ideia da capacidade individual de enfrentar a violência.

2. Exposição a conteúdos violentos na televisão e crenças sobre a realidade social - Para testar a importância que a exposição a programas televisivos violentos, o género e o nível sócio-profissional dos pais, têm sobre as crenças relativas à realidade social, efectuámos três ANOVAs, a cada um dos três factores da percepção da realidade social encontrados e correspondente ao seguinte plano: Exposição a violência na televisão (alta,média, baixa) $x$ Género (rapazes, raparigas) $x$ N.S.P (alta, média, baixa).

Verificou-se ser o Medo Social - Controlo Interno o único factor a ser sensível à variável exposição a violência televisiva. Com efeito, observou-se um efeito principal da exposição a conteúdos televisivos violentos para esta dimensão da realidade social $[F(2,223)=20,59, p<0,001)$, $\left.M S E=0,345, \eta^{2}=0,167\right]$, que vai no sentido de os jovens telespectadores que mais assistiam a violência televisiva, mais acentuassem a crença de que existe violência e perigo à sua volta e que o controlo do medo e dessa violência reside nas suas próprias mãos, $\left(M_{\text {alta exp. viol }}=4,11, D P=0,58\right)$, em comparação com os jovens expostos à violência televisiva de forma média $\left(M_{\text {média exp.viol }}=3,61, D P=0,54\right)$ e baixa $\left(M_{\text {baixa exp.viol. }}=3,39, D P=0,85\right)$. Este efeito é, no entanto, qualificado pela interacção desta variável com o nível sócio-profissional dos pais $[F(2,223)=3,51, p=0,009)$, $\left.M S E=0,345, \eta^{2}=0,064\right]$ : assim, quanto maior a exposição à violência no ecrã, mais acentuado o nível de medo de vitimação social aliado à crença na capacidade individual de assegurar a autodefesa, para os telespectadores pertencentes a famílias de nível sócio-profissional alto e médio, mas não para os jovens oriundos das famílias de menor estatuto sócio-profissional, cuja percepção face ao Medo Social - Controlo Interno não variou significativamente em função do seu nível de exposição a violência televisiva (figura 2).

Para responder à segunda questão deste trabalho, nomeadamente, qual a contribuição do tempo de exposição à televisão, da exposição a violência televisiva, do género e do nível socioprofissional dos pais, para explicar o efeito nas crenças dos adolescentes, procedeu-se a uma análise de regressão múltipla, método Stepwise, com o Medo Pessoal-Controlo Externo, a Desconfiança e o Medo Social-Controlo Interno como variáveis critério. A exposição à televisão, a exposição a violência televisiva, o género e o nível socioprofissional dos pais funcionaram como variáveis preditoras. 
Figura 2. Medo Social - Controlo Interno em função da exposição à violência na TV e do nível socioprofissional da família.

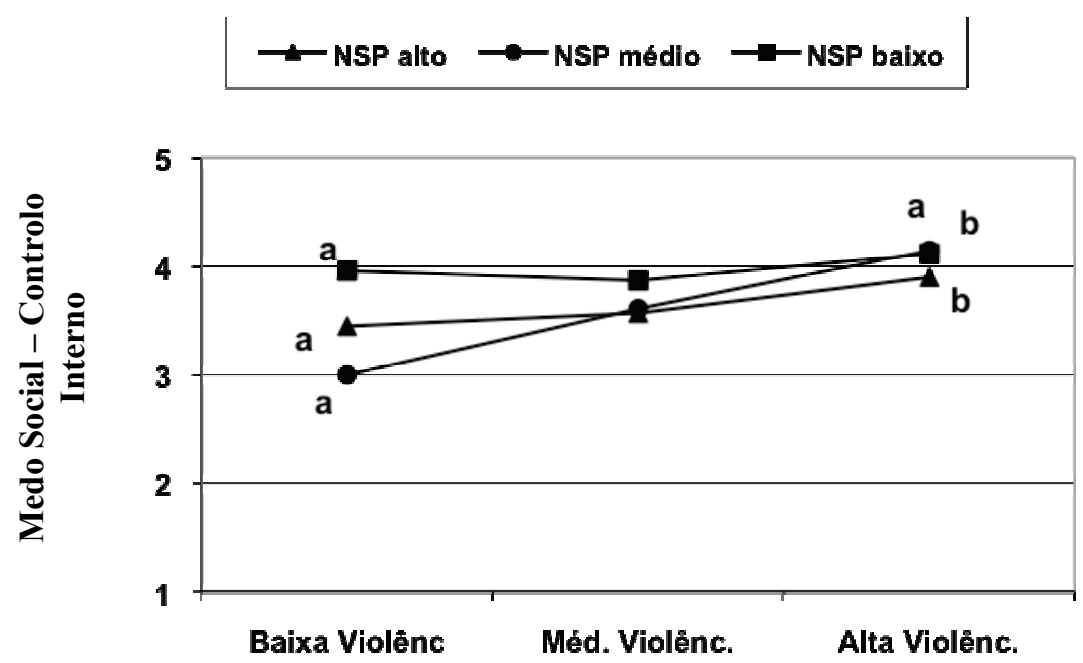

Nota: Médias, por NSP, com letras diferentes, são significativamente diferentes entre si $(p<0,05)$.

O Quadro 5 apresenta os passos efectuados pela regressão múltipla stepwise, os valores de $R^{2}$ ajust. e os coeficientes de regressão normalizados $(\beta)^{12}$.

Para explicar a variância nos resultados do Medo Pessoal-Controlo Externo, apenas duas variáveis contribuíram, de modo significativo para a equação final $[F(2,222)=12,94, p<0,001]$ : o género, que entrou em primeiro lugar na equação, tendo explicado $6,2 \%$ da variância, sendo esta que mais contribui para os resultados do Medo Pessoal-Controlo Externo $(\beta=0,284)$ e o tempo de exposição à televisão que juntamente ao género explicam $10 \%$ da variância dos resultados. As restantes variáveis ficaram fora da equação. ${ }^{13}$ Deste modo poderá supor-se que o nível de medo de vitimação pessoal associado à crença da necessidade de intervenção das

12 Todas as medidas de Medo Pessoal-Controlo Externo, Desconfiança e Medo Social-Controlo Interno foram codificadas no sentido de maior medo e maior desconfiança; as medidas de exposição televisiva foram codificadas no sentido de maior tempo de exposição à televisão e de mais exposição a conteúdos violentos; o nível sócio profissional está codificado no sentido de um maior estatuto sócio-profissional; o género foi codificado de 1 para os rapazes e 2 para raparigas.

$13 \mathrm{O}$ critério para a entrada de uma variável preditora na equação foi a de $\mathrm{p} \leq 0,05$. 
autoridades como forma de garantir a segurança é tanto maior se o género do adolescente for feminino e a quanto mais televisão assistir.

Quadro 5. Análises de regressão múltipla, tendo como variáveis preditoras o género dos participantes, a exposição à TV (tempo e conteúdo violento) e o nível socioprofissional da família, e como variáveis critério os factores de crenças sobre a realidade social.

\begin{tabular}{lclcc}
\hline Variável critério & Passo & Variável predictora & $\mathbf{R}^{2}$ ajust. & $\boldsymbol{\beta}$ \\
\hline $\begin{array}{l}\text { Medo Pessoal - } \\
\text { Controlo Externo }\end{array}$ & 2 & Género & 0,062 & $0,284^{* * *}$ \\
& 1 & Tempo de exp. à TV & 0,100 & $0,206^{* *}$ \\
Desconfiança & 2 & Nível sócio-profis. & 0,068 & $-0,161^{* *}$ \\
& 1 & Exp. à Violência TV & 0,171 & $0,366^{* * *}$ \\
$\begin{array}{l}\text { Medo Social - } \\
\text { Controlo Interno }\end{array}$ & 2 & Tempo exp. à TV & 0,198 & $0,184^{* *}$ \\
\hline
\end{tabular}

Nota: ${ }^{*} p<0,05 ;{ }^{* *} p<0,01 ;{ }^{* * *} p<0,001$

Em relação à Desconfiança, só o tempo de exposição à televisão e o nível socio-profissional dos pais surgem como preditores, contribuindo em conjunto, de modo significativo, para a equação final $[F(2,221)=8,87$, $p=0,001]$, explicando $6,8 \%$ da variância total dos resultados da desconfiança $\left(R^{2}\right.$ ajust. $\left.=0,068 ; N=221\right)$. O tempo de exposição à televisão foi a primeira variável a entrar na equação, explicando $4,7 \%$ da variância, sendo a que mais contribuiu para esses resultados $(\beta=0,180, p=0,008)$. Assim, poderá supor-se que a desconfiança em relação aos outros é tanto maior quanto mais televisão vêem os adolescentes e que essa desconfiança é tanto maior quanto menos elevado for o nível sócio-profissional dos seus pais.

Relativamente ao Medo Social-Controlo Interno, surgem como preditoras as duas variáveis relativas à exposição televisiva (tempo e conteúdos violentos) que, em conjunto, contribuem significativamente para a equação final $[F(2,222)=28,48, p=0,000]$ e explicam $19,8 \%$ da variância total nos resultados desta dimensão da realidade social. A exposição a conteúdos especificamente violentos na televisão foi a primeira variável a entrar na equação, explicando $17,1 \%$ da variância nos resultados, sendo a que mais 
contribuiu para os mesmos $(\beta=0,366)$. Registou-se um menor efeito do tempo de exposição à televisão em geral $(\beta=0,184)$, que apenas explicou $2,7 \%$ da variância observada, ao entrar na equação juntamente com a exposição a violência na TV. Poderá pois supor-se que a crença de que a violência e o perigo existem à nossa volta e que a melhor defesa reside nas nossas próprias mãos (i.e. Medo Social-Controlo Interno) será mais forte quanto maior for o tempo de exposição à televisão mas sobretudo e em especial, quanto maior for a exposição aos conteúdos violentos no ecrã.

\section{Discussão}

Este estudo teve como principais objectivos: 1) verificar a existência da relação prevista pela teoria da cultivação de crenças de Gerbner e colaboradores, entre a exposição à televisão (em tempo e conteúdos especificamente violentos) e determinadas dimensões da realidade social, (tais como o medo de vitimação, o sentimento de desconfiança em relação aos outros e a crença na impotência que têm os indivíduos de controlarem, por si sós, a falta de segurança que percepcionam, e analisar em que medida as variáveis sociodemográficas e as variáveis referentes à exposição à televisão (tempo e conteúdo), permitem entender a existência de diferenças na estrutura da percepção da realidade social dos jovens. 2) averiguar qual o melhor preditor no que respeita às crenças dos adolescentes: se varáveis sociodemográficas, se o tempo de exposição televisiva, ou a exposição a determinado tipo de programas, nomeadamente de programas de conteúdos violentos.

Relativamente ao primeiro objectivo, os resultados deste estudo apontam para o facto de que a exposição à televisão contribui para alterar as crenças dos adolescentes da nossa amostra, se bem que não de forma tão linear como inicialmente prevista por Gerbner e seus colaboradores. Em primeiro lugar, verificou-se que a alta exposição à televisão acentuou, na dimensão Medo Pessoal-Controlo Externo, os estereótipos do género, enfatizando uma certa submissão feminina: com o aumento da exposição à televisão, as raparigas, principais vítimas passivas da programação televisiva (Gerbner \& Gross, 1976; Monteiro 1999) acentuam a crença na possibilidade de virem a ser vítimas, apelando mais à segurança através da intervenção das autoridades e sentindo-se impotentes para enfrentar sozinhas essa ameaça. Pelo contrário, os rapazes, principais agressores na programação televisiva, embora também pertencentes a um grupo importante de vítimas activas (Vala, Lima \& Jerónimo, 2000) reduziram significativamente o medo de virem a ser vítimas de violência ao ultrapassar as 3 horas diárias de exposição à televisão, não apelando às forças policiais para os proteger em caso de violência e acreditando na sua capacidade de controlo pessoal face à 
ameaça, reproduzindo o mundo virtual da televisão onde é possível enfrentar a violência, como os seus heróis pró-sociais preferidos no ecrã (Monteiro, 1999) e punir os "maus" para que o "bem" vença, sendo esta uma lição dominante do mundo televisivo (Potter, 1990).

Este resultado contraria os dados obtidos na meta-análise de Shanahan e Morgan (1999) que revelaram que o género (assim como a maior parte das demais variáveis sociodemográficas) não se mostra moderador dos efeitos de cultivação relatados pelos autores.

No que respeita à Desconfiança, constatámos que os efeitos de cultivação de crenças ficam confinados aos jovens pertencentes à dita "classe média". Com efeito, são os telespectadores mais assíduos e oriundos de famílias de nível socioprofissional médio, que mais acentuam a percepção na falta de bondade e disponibilidade das pessoas para ajudarem os outros. Assim, quanto mais tempo estes jovens passam a ver televisão, mais reticentes se mostram em relação à possibilidade de procurarem apoio junto de outras pessoas, exprimindo que o melhor é desconfiar da maior parte delas, já que "todo o cuidado é pouco ao lidar com elas".

No que respeita ao Medo Social-Controlo Interno registámos que, quanto maior é o consumo televisivo mais se acentua o medo social associado à percepção na capacidade individual de enfrentar a violência. Esta constatação poderá ser explicável à luz do estudo de Monteiro (1999) sobre o consumo da televisão e heróis preferidos dos jovens espectadores dos anos 90, segundo o qual ver muita televisão corresponde a preferir heróis violentos mas pró-sociais (e.g., Mcgyver e Superboy): estes são personagens jovens, corajosos, e socialmente empenhados, só recorrendo à violência quando necessário, exibindo uma violência instrumental tendo como valor a reposição da ordem politica e social através da punição dos infractores e com quem os jovens se vão identificar jogando um papel decisivo na sua construção da percepção sobre a realidade social. Registámos igualmente que a dimensão Medo Social-Controlo Interno é sensível, não só ao tempo de exposição à televisão, mas também à exposição a programas de teor violento, no sentido em que, quanto mais violência televisiva virem os jovens, mais acentuados são os níveis de medo social associado à crença na capacidade individual de assegurar a autodefesa.

De referir ainda a interacção encontrada entre o nível socioprofissional dos pais e a exposição a programação violenta, no que respeita ao Medo Social-Controlo Interno. Para os jovens de N.S.P. alto e médio, a maior exposição a programação violenta eleva a crença que existe violência e perigo à sua volta e que o controlo do medo e dessa violência reside nas suas próprias mãos. Nos jovens pertencentes a famílias de N.S.P. inferior o efeito de cultivação de crenças não de verificou, pois os valores de Medo Social-Controlo Interno registados, mostraram-se identicamente elevados 
independentemente da sua exposição à programação violenta ser reduzida ou elevada. Estes resultados podem ser explicados à luz do conceito de $\mathrm{Cul}$ tura Dominante (mainstreaming) desenvolvido por Gerbner et al. (1982), que defende que os telespectadores mais assíduos tendem a desenvolver perspectivas do mundo semelhantes: neste estudo verificou-se que o aumento da exposição a programas violentos desenvolveu nos jovens pertencentes a famílias de estatuto socioprofissional superior, níveis de Medo Social-Controlo Interno semelhantes e igualmente elevados aos encontrados nos adolescentes oriundos de famílias de nível socioprofissional mais baixo.

Quanto ao segundo objectivo deste estudo - averiguar qual o melhor preditor no que respeita às crenças dos adolescentes - verificámos que o tempo de exposição à televisão foi a variável preditora significativa de todas as dimensões da realidade social analisadas. O género dos inquiridos e o tempo de exposição à televisão foram as variáveis que mais contribuíram para explicar a variância nos resultados do Medo Pessoal-Controlo Externo, tendo sido o género o preditor mais forte. $\mathrm{O}$ tempo de exposição à televisão e o nível socioprofissional dos pais dos jovens foram os preditores dos sentimentos de desconfiança que os jovens sentem em relação aos outros.

Constatou-se, pois, que, para as duas dimensões da realidade social O Medo Pessoal-Controlo Externo e a Desconfiança - a exposição a programas especificamente de teor violento não contribuiu para explicar a variância nos resultados, indo no sentido da visão defendida por Gerbner e que sustenta que os efeitos de cultivação de crenças estão ligados ao uso ritualista e não selectivo da televisão por parte dos telespectadores, sendo a televisão essencialmente uniforme na apresentação das suas mensagens simbólicas sobre a sociedade (Gerbner \& Gross, 1976).

Já no que diz respeito ao Medo Social-Controlo Interno, este será mais acentuado quanto maior for o tempo de exposição à televisão, mas sobretudo e em especial, quanto maior for a exposição aos conteúdos violentos, tendo sido esta a variável que mais contribuiu para explicar os resultados desta dimensão da realidade social. Este último resultado vai ao encontro das conclusões de Hawkins e Pingree (1981) e de Rubin, Perse e Taylor (1988), que consideram os efeitos de cultivação mais ligados ao tipo de programas seleccionados do que ao tempo total de exposição (Hawkins e Pingree, 1981; Rubin et al., 1988). Assim, este último resultado sugere que um telespectador assíduo, que passa a maior parte do tempo a assistir a programas de conteúdos violentos, acentuará a crença na existência de violência e crime na sociedade em geral (sem que o medo seja personalizado) acreditando na virtualidade positiva da autodefesa, relativamente a outro telespectador não tão exposto a programação violenta mas assistindo, os dois, ao mesmo número de horas de televisão. 
De salientar igualmente os baixos valores de variância explicada encontrados. Com efeito, estes resultados vão ao encontro daqueles obtidos pela meta-análise de Shanahan e Morgan (1999), que verificaram que a magnitude do efeito entre a exposição à televisão e a cultivação de crenças se revelou fraca (na ordem dos 0.10) mas significativa. Como referem estes autores, se considerarmos que os efeitos da exposição à televisão são cumulativos e consistentes, uma magnitude do efeito desta ordem poderá fazer uma importante e grande diferença a longo prazo.

Procurámos mostrar, ao longo deste trabalho, que existe uma relação significativa entre o tempo de exposição em primeiro lugar, e os conteúdos veiculados pelo ecrã de televisão em segundo lugar e a construção da visão de um mundo semelhante àquele que é exposto quotidianamente pelos canais de televisão aos jovens espectadores portugueses. Verificámos que essa relação não é tão linear como acreditava Gerbner e seus colaboradores ao lançarem as bases da teoria da cultivação de crenças, mas constatámos que ela existe e que não pode ser descartada. $\mathrm{O}$ estudo das contingências e natureza dessa relação (i.e., impacto da televisão versus construção da realidade social), é precisamente um desafio motivador que precisa ser mais bem esclarecido (e.g., pelo estudo de outras variáveis potencialmente influentes nos processos de cultivação de crenças). Desta forma, poderemos interpretar melhor as idiossincrasias que advêm da maneira como as sociedades se relacionam com o fenómeno televisivo e reflectir com propriedade científica e não meras especulações, mesmo que bem intencionadas, sobre o papel que a televisão desempenha nas nossas vidas.

\section{Referências}

American Academy of Pediatrics (2001). Children, adolescents and television. Pediatrics, 107, 423-426.

Bandura, A. (1973). Aggression: A social learning analysis. Englewood Cliffs, New Jersey: Prentice-Hall.

Bandura, A., (1977). Social learning theory. Englewood Cliffs, New Jersey: Prentice-Hall.

Bandura, A., \& Walters, R. (1963). Social learning and personality development. Holt: New York.

Bandura, A., Ross, D., \& Ross, S. A. (1961). Transmission of aggression through imitation of aggressive models. Journal of Abnormal and Social Psychology, $63,575-582$.

Berkowitz, L., (1962). Aggression: A social psychological analysis. New York: McGraw-Hill. 
Berkowitz, L., \& Rawlings, E. (1963). Effects of film violence on inhibitions against subsequent aggression. Journal of Abnormal and Social Psychology, 66 (5), 405-412.

Bryant, J., Carveth, R. A., \& Brown, D. (1981). Television viewing and anxiety: An experimental examination. Journal of Communication, 31(1), 529-552.

Carveth, R., \& Alexander, A. (1985). Soap opera viewing motivations and the cultivation process. Journal of Broadcasting and Electronic Media, 29(3), 259-273.

Eschholz, S. (2002). Racial composition of television offenders and viewers' fear of crime. Critical Criminology, 11, 41-60.

Evra, J. (1990). Television and child development. Hillsdale, NJ: Lawrence Erlbaum.

Feshbach, S., \& Singer, R. D. (1971). Television and aggression: An experimental field study. San Francisco: Jossey-Bass.

Gerbner, G. (1972). The violence profile: Some indicators of trends in and the symbolic structure of network television drama 1967-1971. In Surgeon General's Report by the Scientific Advisory Committee on Television and Social Behaviour, Appendix A (pp.453-526). Washington, DC: US Government Printing Office.

Gerbner, G. (1990). Epilogue: Advancing on the Path for Righteousness (maybe). In N. Signorielli \& M. Morgan (Eds.), Cultivation analysis: New directions in media effects research (pp. 249-262). Newbury Park, Sage.

Gerbner, G., \& Gross, L. (1976). Living with television: The violence profile. Journal of Communication, 26 (2), 172-199.

Gerbner, G., Gross, L., Morgan, M., \& Signorielli, N. (1980a). The mainstream of America: Violence Profile $n^{\circ} 11$. Journal of Communication, 30(3), 10-29.

Gerbner, G., Gross, L., Morgan, M., \& Signorielli, N. (1980c). Media and family: Images and impact. Paper for the National Research Forum on Family Issues. White House Conference on Families.

Gerbner, G., Gross, L., Morgan, M., \& Signorielli, N. (1982). Charting the mainstream: Television's contributions to political orientations. Journal of Communication, 32(2), 100-127.

Gerbner, G., Gross, L., Morgan, M., \& Signorielli, N. (1984). Political correlates with television viewing. Public Quarterly, 48(1), 283-300.

Gerbner, G., Gross, L., Morgan, M., \& Signorielli, N. (1986). Living with television: The dynamics of the cultivation. In J. Bryant \& D. Zillmann (Eds.), Perspectives on media effects (pp. 17-40). Hillsdale, NJ: Lawrence Erlbaum Associates.

Gerbner, G., Gross, L., Morgan, M., \& Signorielli, N. (1994). Growing up with television: The cultivation perspective. In J. Bryant \& D. Zillmann (Eds.), Media effects: advances in theory and research, (pp. 17-42). Hillsdale, NJ: Lawrence Erlbaum Associates.

Gerbner, G., Gross, L., Jackson-Beeck, M., Jeffries-Fox, S., \& Signorielli, N. (1978). Cultural indicators: Violence profile $n^{\circ}$ 9. Journal of Communication, 28(3), 176-207.

Gerbner, G., Gross, L., Morgan, M., Signorielli, N. \& Shanahan, J. (2002). Growing up with television: Cultivation processes. In J. Bryant \& D. Zillmann (Eds.), 
Media effects: Advances in theory and research (pp. 43-67). Hillsdale, NJ: Lawrence Erlbaum Associates.

Gerbner, G., Gross, L., Signorielli, N., \& Morgan, M. (1980b). Aging with television: Images on television drama and conceptions of social reality. Journal of Communication, 30(1), 37-47.

Gerbner G., Gross L., Signorielli, N., Morgan, M., \& Jackson-Beeck, M. (1979). The demonstration of power: Violence profile $\mathrm{n}^{\mathrm{o}} 10$. Journal of Communication, 29(3), 177-196.

Gerbner, G., \& Signorielli, N. (1979). Women and minorities in television drama, 1969-1978. Philadelphia: The Annenberg School of Communication, University of Pennsylvania.

Goidel, K., Freeman, C., \& Procopio, S. (2006). The impact of television viewing on perceptions of juvenile crime. Journal of Broadcasting and Electronic Media, 50(1), 119-139.

Gosselin, A., DeGuise, J., Pacquette, G., \& Benoit, L. (1997). Violence on Canadian television and some of its cognitive effects. Canadian Journal of Communication, 22(2), 140-160.

Gunter, B., \& Wober, M. (1983). Television viewing and public trust. British Journal of Social Psychology, 22, 174-176.

Hawkins, R., \& Pingree, S. (1981). Uniform messages and habitual viewing: Unnecessary assumptions in social reality effects. Human Communication Research, 7(4), 291-201.

Hetsroni, A., \& Tukachinsky, R. H. (2006). Television-world Estimates, real-world estimates, and television viewing: A new scheme for cultivation. Journal of Communication, 56 (1), 133-156.

Hoover, M. S. (1990). Television and religion. In N. Signorielli, \& M. Morgan (Eds.). Cultivation analysis: New directions in media effects research (pp. 123-140). Newbury Park: Sage.

ISCTE/ ERC (2007). Estudo de recepção dos meios de comunicação social. Estudo promovido pela Entidade Reguladora da Comunicação Social e desenvolvido no âmbito do ISCTE. Divulgado na conferência da ERC em Outubro de 2008. http://www.erc.pt/index.php?op=conteudo\&lang=pt\&id=198\&mainLevel=folh aSolta.

INE (2001). Inquérito à ocupação do tempo, 1999. Instituto Nacional de Estatistica, Portugal.

INE (2002). O tempo das crianças : Inquérito à ocupação do tempo, 1999. Instituto Nacional de Estatistica, Portugal.

Kuntsche, E., Pickett, W., Overpeck, M., Craig W., Boyce, W., \& Gaspar de Matos, M. (2006). Television viewing and forms of bullying among adolescents from eight countries. Journal of Adolescent Health, 39, 908-915.

Linz, D., Donnerstein, E., \& Penrod, S. (1988). Effects of long-term exposure to violent and sexually degrading depictions of women. Journal of Personality and Social Psychology, 55(5), 758-768.

Marktest (2007, Outubro, 4). Aumenta consumo de televisão: audiências de televisão. http://www.marktest.com/wap/a/n/id f04.aspx. 
Mastro, D., Behm-Morawits, E., \& Ortiz, M. (2007). The cultivation of social perception of latinos: A mental models approach. Media Psychology, 9, 347-365.

Monteiro, M. B. (1984). La Construction sociale de la violence: Approche cognitive et développementale (Thèse de doctorat en Psychologie). Université Catholique de Louvain.

Monteiro, M. B. (1999). Meios de comunicação social e construção da realidade social: Crescer com a violência em Portugal. Psicologia, 12(2), 320-339.

Morgan, M. (1982). Television and adolescent's sex-role stereotypes: A longitudinal study. Journal of Personality and Social Psychology, 43(5), 947-955.

Morgan, M. (1983). Symbolic victimization and real-world fear. Human Communication Research, 9, 146-157.

Morgan, M. (1990). International cultivation analysis. In N. Signorielli, \& M. Morgan (Eds.), Cultivation analysis: New directions in media effects research (pp. 225-248). Newbury Park: Sage,.

Morgan, M., \& Signorielli, N. (1990). Cultivation analysis: Conceptualization and methodology. In N. Signorielli, \& M. Morgan (Eds.), Cultivation analysis: New directions in media effects research (pp. 13-34). Newbury Park: Sage.

Murray, J. (2007). TV violence: research and controversy. In N. Pecora, J. Murray \& E. A. Wartella (Eds.), Children and television: Fifty years of research (pp. 183-203). New Jersey: Lawrence Erlbaum Associates, Inc.

Pecora, N. (2007). The changing nature of children's television: Fifty years of research. In N. Pecora, J. Murray \& E. A. Wartella (Eds.), Children and television: Fifty years of research (pp. 1-40). New Jersey: Lawrence Erlbaum Associates, Inc.

Pew Research Center for People \& The Press (2008). Audience segments in a changing news environment. http://people-press.org/reports/pdf/444.pdf

Potter, J. (1990). Adolescents' perceptions of the primary values of television programming. Journalism Quarterly, 64(4), Winter, 843-851.

Rideout, V., Vandewater, E., \& Wartella, E. A. (2003). Zero to six: Electronic media in the lives of infants, toddlers and preschoolers - Report. Washington, D. C., Kaiser Amily Foundation. www.kff.org/entmedia/3378.cfm.

Roberts, D., Foher, U., \& Rideout, V. (2005). Generation M: Media in the lives of 08-18 years olds. Washington, D.C., Kayser Family Foundation. http://www.kff.org/entmedia/7251.cfm.

Rubin, A., Perse, E., \& Taylor, D. (1988). A methodological examination of cultivation. Communication Research, 15(2), 107-134.

Shanahan, J., \& Morgan, M. (1999). Television and its viewers: Cultivation theory and research. Cambridge: Cambridge University Press.

Shrum, L. J. (2007). The implications of survey method for measuring cultivation effects. Human Communication Research, 33, 64-80.

Signorielli, N. (1990). Television's mean and dangerous world: A continuation of the cultural indicators perspective. Cultivation analysis: New directions in media effects research (pp. 85-106). Newbury Park: Sage.

Signorielli, N. (1992). Unhealthy messages. Health Communication, 4, 245-257. 
Signorielli, N. (2005). Violence in the media: A reference handbook. Santa Barbara, CA: Abc-Clio.

Signorielli, N., \& Morgan, M. (1990). Cultivation analysis: Conceptualization and methodology. In N. Signorielli \& M. Morgan (Eds.), Cultivation analysis: New directions in media effects research (pp. 13-34). London: Sage Publications.

Strasburger, V. C. (1989). Adolescent sexuality and the media. Paediatrics Clinics of North America, 36 (3), 747-773.

Strasburger, V. C. (2008). Anything goes! teenage sex and the media. Journal of Obstetrics and Gynaecology Canada, 30(2), 109-111.

Tannenbaum, P. H., \& Zillmann, D. (1975). Emotional arousal in the facilitation of aggression through communication. In L. Berkowitz (Ed.), Advances in Experimental Social Psychology Vol. 8, 150-193. New York: Academic Press.

Tyler, T. R., \& Lomax Cook, F. (1984). The mass media and judgments of risk: distinguishing impact on personal and societal level judgments. Journal of Personality and Social Psychology, 47(4), 693-708.

Vala, J. (1984). La production social de la violence: Représentations et comportements, (Thèse de doctorat en Psychologie). Université Catholique de Louvain.

Vala, J., Lima L., \& Jerónimo, R. (2000). Avaliação da violência na televisão portuguesa: Programação 1997. Lisboa: Alta Autoridade para a Comunicação Social.

Volgy, J. T. \& Schwarz, J. (1980). TV entertainment programming and socio-political attitudes. Journalism Quarterly, 57, 150-155.

Wober, M. (1978). Televised violence and paranoid perception: the view from Great Britain. Public Opinion Quarterly, 42(3), 315-321.

Wober, M., \& Gunter, B. (1982). Television and personal treat: Fact or artefact? A British survey. British Journal of Social Psychology, 21, 239-247.

Wober, W., \& Gunter, B. (1985). Patterns of television viewing and of perceptions of hazards to life. Journal of Environmental Psychology, 5, 99-108.

Wober, M. (1978). Televised violence and paranoid perception: The view from Great Britain. Public Opinion Quarterly, 42(3), 315-321.

Zaharopoulos, T. (2000). Media consumption and the perception of traditional sex roles in Greece. International Communications Bulletin, Volume 35, $\mathrm{n}^{\mathrm{o}}$ 1-2 (Spring), 22-26.

Zillmann, D. (1971). Excitation transfer in communication mediated aggressive behaviour. Journal of Experimental Social Psychology, 7, 419-493. 